\title{
Tick-borne encephalitis in domestic animals
}

\author{
J. SALAT, D. RUZEK
}

\author{
Department of Virology, Veterinary Research Institute, Hudcova 296/70, 62100 Brno, Czech Republic
}

\begin{abstract}
Summary. - Tick-borne encephalitis (TBE), a disease caused by tick-borne encephalitis virus (TBEV), represents a serious neural infection of humans in Europe and Asia. The main reservoir hosts of TBEV are ticks, rodents and insectivores, but domestic animals may also be infected with the virus. This review summarizes what is known about TBE in domestic species (e.g., dogs, horses), in which infection may manifest with clinical signs similar to those seen in severe human cases. We also focus on TBE in ruminants where TBE infections are typically asymptomatic and do not cause health problems in the infected hosts. However, the risk to human health is the main problem of asymptomatic infection, because the presence of TBEV in the milk of infected ruminants can serve as a source of TBE infection via the alimentary route. An experimental veterinary vaccine was developed recently, and future vaccination of selected domestic animals is proposed to avoid the development of severe TBE symptoms in sensitive animals (e.g., dogs, horses) or to decrease the risk of alimentary infection in humans (e.g., goats and sheep).
\end{abstract}

Keywords: tick-borne encephalitis; dog; goat; sheep; cow; horse

\section{Introduction}

Tick-borne encephalitis (TBE) is a serious infectious human disease affecting the central nervous system (CNS) (Ruzek et al., 2019). Between 10,000 and 15,000 cases are reported in Europe and Asia annually (Bogovic and Strle, 2015). The causative agent of the disease, TBE virus (TBEV), is a representative of arboviruses, i.e. viruses, which are transmitted by blood-sucking arthropods. Taxonomically, the virus belongs to the Flaviviridae family, the genus Flavivirus (Simmonds et al., 2017). The viral genome is a single-stranded RNA encoding one polyprotein that is cleaved into three structural (C, M, E) and seven non-structural proteins. The nucleocapsid of the virus consists of the viral nucleic acid and capsid protein $C$. The nucleocapsid is enveloped by a lipid membrane containing proteins $\mathrm{M}$ and $\mathrm{E}$ (Fuzik et al., 2018). The main surface antigen is protein E, which allows binding with the surface receptors of the host cells to mediate infection (Heinz, 1986).

E-mail: salat@vri.cz; phone: +420-533331101.

Abbreviations: $\mathrm{CNS}=$ central nervous system; $\mathrm{TBE}$ = tick-borne encephalitis; $\mathrm{TBEV}=\mathrm{TBE}$ virus
Transmission of the virus to humans usually occurs during infestation by the infected tick, while the alimentary route is a less frequent way of transmission after consumption of milk or milk products containing TBEV. The main TBE vectors are ticks of the genus Ixodes. Therefore, the incidence of TBE is closely related to the expansion of these parasites and their activity at certain times of the year. The ongoing global climate changes contribute to the introduction of the tick population and spread of TBEV to new localities and higher altitudes (Kř́ž et al., 2009). The virus is transmitted both transovarially and transstadially between developmental stages. Small rodents are considered to play an essential role in maintaining TBEV infection foci, where other ticks get infected during viremia or via co-feeding on small rodents with infected ticks (Nuttal et al., 1994). Large vertebrate hosts (e.g., wild animals, grazing domestic animals, and birds) play an essential role in the successful completion of the tick life cycle, as well as in transmission of ticks (including TBEV-infected ones) to new regions (Nuttal et al., 1994). Humans can be accidental hosts of all tick life stages and become infected with TBEV. The most serious form of TBE in humans manifests as encephalomyelitis (inflammation of the brain and spinal cord) (Gritsun et al., 2003). In European countries, the TBE case fatality rate is as high 
as $1 \%$. The severity of the disease increases with the age of the patient (Lindquist and Vapalahti, 2008). Currently, no specific therapy with a direct antiviral effect is available for TBE. In addition to general rules for preventing tick infestation, including the application of repellent products, vaccination is the most effective preventive measure against TBE (Kunz, 2003).

The main reservoir hosts of TBEV are ticks, rodents and insectivores. Both ticks as well as small mammals play a crucial role in the maintenance of a TBE foci in nature; however, accidental hosts may also be infected with the virus, including humans, domesticated animals, and captive exotic animals in TBE-endemic areas. Such infections pose a health risk to pets, in which the disease may manifest with clinical signs similar to those seen in severe human cases. Another risk is asymptomatic infection of farm animals, which constitutes a potential risk to humans in terms of the transmission of TBE infection via the alimentary route.

\section{Dogs}

\section{Disease}

As in other vertebrates, TBE is transmitted to dogs by infected ticks while they feed on their hosts. Similar manifestations as in human disease are observed in the case of the development of serious disease, which often takes a severe course, occasionally even with a fatal outcome (Pfeffer and Dobler, 2011). The duration of the TBE incubation period in dogs is estimated to be 1-2 weeks, which is supposed to be equivalent to the disease course in humans (Leschnik et al., 2002). Common manifestations of TBE in dogs include an elevated body temperature up to $41.4^{\circ} \mathrm{C}$ and change in the behavior of the animals, such as denying food, increased aggressiveness, shyness, and apathy. Musculoskeletal disorders are often found in diseased animals, with forelimb and hind limb motion abnormalities being the most common. The following signs have been revealed by neurological examination: paresis of the forelimbs or hind limbs, quadriplegia, seizures, convulsions, ataxia, perceptual disorders, hyperalgesia in the neck, hyperesthesia, loss of head sensitivity, facial nerve paralysis, strabismus, anisocoria, nystagmus, miosis, loss of the corneal reflex, and optical neuritis. All of these manifestations are indicative of severe neurological damage to the cerebellum and brainstem (Pfeffer and Dobler, 2011). Based on seroprevalence studies, it is clear that dogs are susceptible hosts to TBEV infection. TBEV seroprevalence in dogs has been performed in several countries with the following results: Austria 13.3\% (Leshnik et al., 2013), Belgium 0.1\%
(Roelandt et al., 2011), Czech Republic 3.3-11.3\% (Klimeš et al., 2001; Hekrlová et al., 2015), Denmark 4.8-30\% (Lindhe et al.,2009), Finland 6-40\% (Levanov et al., 2016), Germany 2.1-42.7\% (Reiner et al., 2002; Balling et al., 2014), Greece 1-8\% (Chambouris et al., 1989), and Norway 16.4\% (Csángó et al., 2004). Canine TBEV infection is frequent in endemic areas, with a calculated annual risk of infection of approximately $11.6 \%$ (Leschnik et al., 2013). However, the infection manifests clinically in only a small proportion of infected canines, and severe manifestations occur only in rare cases. Nevertheless, this disease should be considered in dogs with neurological disorders or abnormal behavioral changes.

Hematological analysis performed in a sick animal usually shows total leukocytes within the normal range. In some cases, hematology has shown leukopenia, lymphopenia, and monocytosis. Increased total leukocyte count (especially mononuclear cells) and high protein concentration in the cerebrospinal fluid are typical indicators of ongoing brain inflammation and have been described in clinical canine TBE (Pfeffer and Dobler, 2011). A typical pathological finding associated with TBE in dogs is massive encephalitis with no evidence of histopathological lesions in visceral organs. Non-suppurative meningoencephalitis and necrosis of both neurons and glial cells are observed. Almost the entire brain presents signs of ongoing inflammation, especially the presence of cell infiltrates (lymphocytes, histiocytes, and plasma cells). The most prominent gross lesions are found in the cerebellum and the brainstem (Weissenböck et al., 1998). Gross lesions in certain parts of the brain are related to specific clinical manifestations of the disease: fever, altered consciousness and behavior (thalamus, cerebral cortex), proprioceptive deficit (mesencephalon), motor neuron deficit (spinal cord), hyperalgesia in the neck (meninges), facial paresis, nystagmus, strabismus (brainstem), and seizures (cerebellum, thalamus) (Weissenböck et al., 1998).

\section{Diagnosis}

TBEV can be detected in serum by RT-PCR during viremia (Schwaiger and Cassinotti, 2003), but this examination is not widely used in clinical practice because the animal is usually examined in the post-viremia phase of the disease. In brain tissue post-mortem, TBEV can be isolated using culture methods, viral RNA can be detected by RT-PCR, and viral antigen can also be demonstrated immunohistochemically (Weissenböck et al., 1998). However, in most cases the TBE diagnosis relies on serological detection of specific antibodies, with ELISA being used most often to determine the specific antibody titer in the tested serum. In endemic areas, up to $30 \%$ of examined dogs are 
seropositive for TBEV (Pfeffer and Dobler, 2011); therefore, it is important to compare ELISA antibody titers in paired sera 2 weeks apart. Only increased IgG antibody titers or the presence of IgM antibodies indicate acute infection (Lindhe et al., 2009).

\section{Treatment}

Treatment of TBE in dogs is solely symptomatic (Pfeffer and Dobler, 2011). Emphasis should be placed on preventing the animal's injury as a result of behavioral changes, particularly due to increased aggressiveness. Therefore, therapy should include sedatives and antipyretics, and antibiotics to prevent secondary bacterial infections, particularly the development of pneumonia (Kritz et al., 2001). The administration of dexamethasone because of its anti-inflammatory effect is controversial. When given at an early phase of disease, it may prolong virus replication in the CNS and cause more severe brain damage. On the other hand, when glucocorticoids are administered during the convalescence phase, fast relief of TBE symptoms is observed (Tipold et al., 1993). The convalescence time in most TBE cases in dogs has ranged from 6 to 12 months. As in humans, long-term physical therapy appears to play a central role in the recovery process. The physical therapy gradually leads to functional replacement of damaged areas in the CNS through compensation and training (Pfeffer and Dobler, 2011).

\section{Prevention}

Preventive measures to avoid TBEV infection in dogs are based primarily on reducing infestation by infected ticks. Products with long-term repellent and acaricidal properties can be applied to the hair of the animals. Acaricides, such as amitraz, fipronil, and permethrin, have been shown to have tick-repellent activity in numerous studies (Dryden, 2009). Naturally, when applying a repellent product, it is necessary to consider the advantages and disadvantages of its long-term use with regard to the potential toxic effects on the health of the exposed dogs (Berrada and Telford, 2009). Therefore, the long-term application of repellents is primarily recommended in areas with endemic tick-transmitted infections, where the benefit of their use significantly outweighs their possible adverse effects. Currently available TBE vaccines used in Europe are licensed for human use only. The protective effect of these vaccines against TBEV infections in domestic animals has been demonstrated experimentally (Balogh et al., 2011). Therefore, targeted vaccination of dogs against TBE should be considered in highly endemic areas.

\section{Horses}

Studies of the prevalence of TBE-specific antibodies in horses have revealed that this species is also susceptible to TBEV infection, though the disease is asymptomatic in the vast majority of cases. These studies revealed quite high seropositivity in horses kept in TBE-endemic areas in Austria (26.1\%) and Germany (20-30\%) (Klaus et al., 2013; Rushton et al., 2013). However, TBE is diagnosed sporadically in horses. The signs of disease reported in individual cases include poor general condition, loss of appetite, anorexia, shyness, nervousness, ataxia, spasms and epileptic seizures, and hyperalgesia in the neck(Klaus et al., 2013). The animals usually recover within 1 year, sometimes with the persistence of subtle neurological deficits (Klaus et al., 2013). Due to the very low recorded incidence of TBE, its importance in horses has been neglected in veterinary medicine thus far. TBEV infection in horses is usually mentioned in the context of epidemiology, as their susceptibility to the infection and subsequent seroconversion could be used to monitor TBE outbreak areas in the environment (Rushton et al., 2013).

\section{Ruminants}

In ruminants, TBEV infections are asymptomatic and do not typically cause any health problems in the infected host, as has recently been demonstrated in experimental TBEV infection of lambs (Paulsen et al., 2019). However, rare descriptions of symptomatic TBE in ruminants also exist (Böhm et al., 2017). The main problem of infected ruminants is the risk of infection of humans who consume milk and dairy products from the infected animals. The infection via the alimentary route is the second most common means of TBEV transmission to humans. The occurrence of TBE from tick-borne infections is accidental, whereas alimentary infections are characterised by family incidence associated with the consumption of virus-contaminated food (Hudopisk et al., 2013).

\section{Alimentary infection of humans}

Milk from infected goats, sheep, and cows has been identified as a source of human food-borne infections (Grešíková,1999). Animals usually acquire TBEV infection during the grazing period when an infected tick feeds on their blood. Experimentally, transient viremia has been shown to occur after infection with TBEV, which usually lasts for several days in all of the above-mentioned ruminant species; subsequently, the virus is present in milk. In goats and sheep, the virus has been detected in milk 2-7 days after infection (Grešíková, 1957, 1958a). In a more 
recent study, TBEV was detected in the milk of experimentally infected goats as late as 23 days after infection (Balogh et al., 2011). The virus can be found in cow milk from day 2 to 8 after TBEV infection (Grešíková, 1958b).

Human infection can occur via consumption of unpasteurised 'infectious' milk containing a sufficient concentration of viral particles. Notably, TBEV titers in milk can be considerably higher than in blood during viremia (Grešíková, 1999). As an enveloped RNA virus, TBEV is relatively sensitive to changes in physicochemical conditions. However, in milk, the virus can survive exposure to acidic gastric juice ( $\mathrm{pH}$ 1.49-1.80) for up to 2 hours (Pogonina, 1958). Hydrochloric acid is secreted in the stomach 45-60 min after the consumption of milk, which begins to leave the stomach environment within a few minutes after consumption. After 2 hours, all consumed milk is usually found in the lower gastrointestinal tract. With respect to this information, it is clear that the digestive system may be a potential gateway for TBEV infection. Food-borne TBEV infection was verified experimentally in a mouse model (Pogodina, 1960). It is assumed that infection by the alimentary route is transmitted via the intestinal M cells of Peyer's patches. These cells transport the antigen that entered the body with food to immunocompetent cells, and are, therefore, involved in the early immune response against enteral pathogens. In the case of alimentary TBEV infection, M cells may allow the virus to enter the lymphoid tissue, where primary replication occurs. The infection then proceeds with the standard viremic phase and reaches the target organ, the CNS (Balogh et al., 2011). TBEV has also been shown to be able to replicate in human intestinal epithelial Caco- 2 cells and to translocate through the intestinal epithelial barrier (Yu et al., 2014). Food-borne TBE infections are mostly biphasic and usually do not have a severe course or sequelae in the form of permanent neurological damage and paresis, as occurs in the case of infections transmitted by ticks (Gritsun et al., 2003).

\section{TBEV stability in milk and milk products}

TBEV remains stable in milk for a long period of time. The virus is able to survive in milk for up to 2 weeks at $4^{\circ} \mathrm{C}$ with only a modest decrease in titer. However, in saline, a minimum number of viral particles survive under the same storage conditions after 14 days of monitoring (Grešíková, 1959). Thus, milk has a protective effect on TBEV stability and, if contaminated, retains infectivity for consumers throughout its shelf life. Viable virus has been detected in all dairy products tested (sour milk, cream, butter, cottage cheese, yogurt, whey), with the highest persistence of the virus in butter, where no decrease in the baseline titer was observed during 2 months of moni- toring (Grešíková et al., 1959). TBEV can be reliably inactivated in milk through pasteurisation at $72^{\circ} \mathrm{C}$ (Grešíková et al.,1960). The previously recommended heating to $65^{\circ} \mathrm{C}$ (Grešíková,1999) may not be fully effective, as a later study (Balogh et al., 2011) demonstrated that this temperature is not sufficient to completely inactivate TBEV in all contaminated goat milk samples, even after $30 \mathrm{~min}$.

\section{Epidemiology}

Cases of food-borne TBEV infections have been reported in most geographic areas with disease prevalence. The largest epidemic outbreak of TBE caused by consumption of unpasteurised goat milk occurred in Rožňava in the former Czechoslovakia in 1951, when more than 660 people were infected through contaminated milk and 271 of them had to be admitted to the hospital (Blaškovič, 1954). Local outbreaks of small-scale food-borne TBE were recently described in many countries where TBEV is present. A high occurrence of alimentary TBE has been recorded in Slovakia, where 26 alimentary TBE outbreaks were described between 2007 and 2016. The most common probable and confirmed transmission factor for alimentary TBE outbreaks in Slovakia was goat milk and goat milk products (Kerlik et al., 2018). In the period 1997-2008, 64 cases of food-borne TBE were detected in the Czech Republic, corresponding to $0.9 \%$ of all TBE cases diagnosed in the country. The source of alimentary infection was typically fresh goat milk (56.3\%), sheep cheese (32.8\%), and cow milk (10.9\%) (Kř́iž et al., 2009). Local outbreaks of food-borne TBE after consumption of virus-contaminated milk have also been detected in Poland (Matuszczyk et al., 1997; Krol et al., 2019) and Estonia (Kerbo et al., 2005). In addition, cases of TBEV infection following consumption of fresh goat cheese have been reported in Austria (Holzmann et al., 2009). Food-borne TBE outbreaks associated with cow milk have also been reported in Hungary (Caini et al., 2012) and cases associated with goat milk in Slovenia (Hudopisk et al., 2013).

The estimated prevalence of TBE in ruminants in endemic areas is relatively high. A study in Poland revealed that viral RNA can be detected in up to $22.2 \%$, $20.7 \%$, and $11.1 \%$ of milk samples from sheep, goats, and cows, respectively, in TBE risk areas (Cisak et al., 2010). A study performed in Norway detected TBEV RNA in 5.4\% of unpasteurised milk samples collected from farms in the municipalities of Mandal, Skedsmo, and Brønnøy. However, antibodies to TBEV were only detected in Arendal, where $88.2 \%$ of the tested animals were serologically positive (Paulsen et al., 2019). Considerable differences in seroprevalence were detected between single flocks of goats and sheep in Germany in selected districts in Baden-Wuerttemberg, Bavaria, and Thuringia, with 


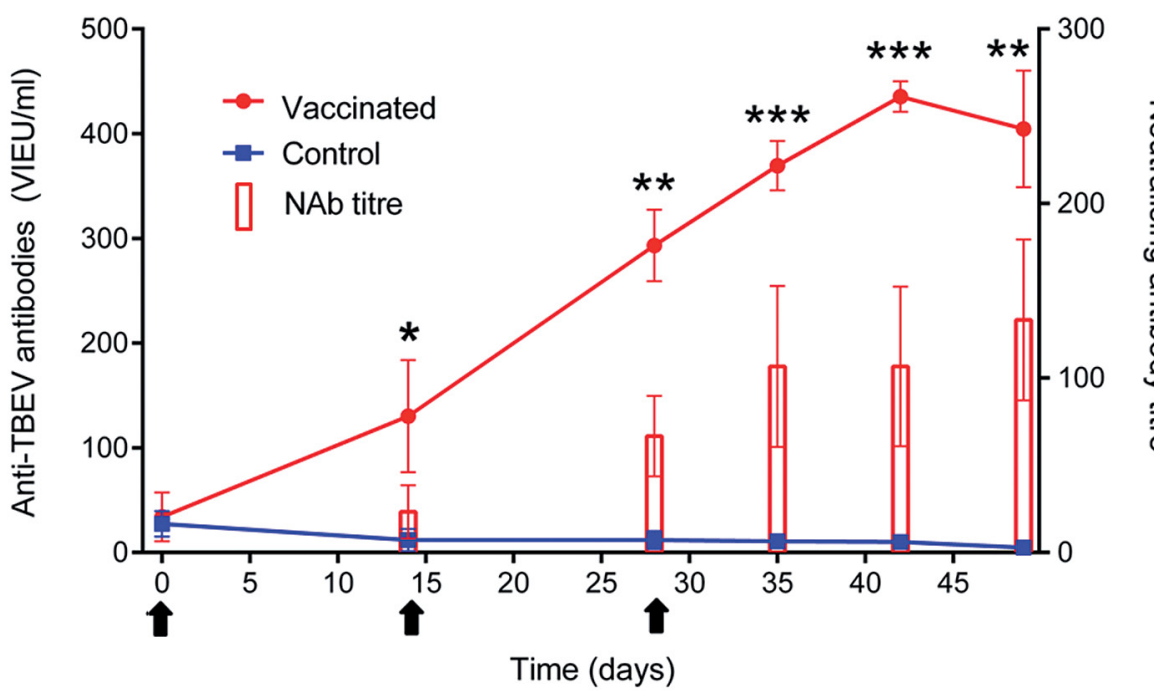

Fig. 1

Vaccination of sheep with a new tick-borne encephalitis virus vaccine candidate for veterinary use

The concentration of specific anti-TBEV antibodies in the sera of vaccinated sheep is shown. Post-vaccination TBEV-specific antibodies were measured by ELISA (lines). Virus neutralising antibody titers (NAb titer) were measured by VNT (columns). Results are shown as the mean \pm S.D. The statistical difference between the vaccinated and control group is indicated by ${ }^{* *} \mathrm{P} \leq 0.01$ and ${ }^{* * *} \mathrm{P} \leq 0.001$. The figure is reprinted with permission (Salát et al., 2018).

values ranging between 0 and 43\% (Klaus et al., 2012). Goats were used as sentinel hosts for the detection of TBE risk areas in the Canton of Valais, Switzerland. The seroprevalence rate in this study was $4.3 \%$. Furthermore, at two of the three locations where goats were seropositive, the local tick populations also tested positive for TBEV (Rieille et al., 2017). Similarly, sheep were used as sentinels for detection of TBE-positive localities in Romania. High antibody prevalence (15\%) was detected among sheep tested in five counties of north-western Romania (Salat et al., 2017)

\section{Experimental vaccination of ruminants}

The consumption of raw milk poses a significant risk of TBEV infection. Therefore, pasteurisation of milk and dairy products is strongly recommended as a standard preventive measure of protection against food-borne TBE infection. Vaccination of farm animals is another potential way to protect consumers from the risk of alimentary TBEV infection. Experimental immunisation of goats with a human vaccine against TBE provided full protection against subsequent TBEV infection, and, consequently, no virus was detected in milk of the vaccinated and TBEV challenged animals (Balogh et al., 2011). Recently, a new veterinary TBE vaccine candidate was developed (Salát et al.,2018). The vaccine is based on whole virus-inactivated antigen. The safety and immunogenicity of the vaccine was evaluated in mice and sheep, and it was well-tolerated while eliciting the production of high levels of virusneutralising antibodies (Fig. 1). Vaccination provided full protection against lethal TBE in mice, and prevented the development of viremia in sheep and the presence of TBEV in the milk of lactating ewes. Therefore, this vaccine is a good candidate for immunisation of ruminants to prevent alimentary milk-borne TBEV infection of humans (Salát et al., 2018).

\section{Exotic animals kept in captivity}

Exotic species kept in captivity can also become accidental hosts of TBEV. The best-known documented TBEV infection in these animals is the case of a macaque (Macaca sylvanus) from the Salem Zoological Park in Germany. The animal developed a fatal TBEV infection with the following signs: lower limb paralysis, loss of coordination, opistotonus, and coma. TBE was diagnosed post-mortem based on the detection of viral antigen in the CNS and the presence of specific anti-TBE antibodies in the animal's serum (Süss et al., 2007). A subsequent serological survey detected specific anti-TBE antibodies in $2.6 \%$ of the macaques kept at the Zoological Park, and a retrospective anamnestic analysis revealed that sporadic TBE cases also occurred in the past in the macaques (Klaus et al., 2010). 
A serological study focused on the prevalence of tickborne diseases in exotic animals kept in zoological gardens in the Czech Republic. A total of 133 serum samples from 69 animal species in five zoological gardens were examined. Specific anti-TBE antibodies were detected in only two cases: a markhor (Capra falconeri) and a reindeer (Rangifer tarandus) (Širmarová et al., 2014). Thus, TBEV infections can occur in captive animals, and severe forms of TBE can occasionally develop in susceptible species.

\section{Conclusions}

Animal TBEV infections are common in virus-endemic areas. In addition to the main reservoir hosts (e.g. ticks, rodents and insectivores), domestic animals may also be infected with the virus. TBEV infection in sensitive domestic animal species (e.g. dogs, horses) can be severe and may manifest with clinical signs similar to those seen in severe human cases. Serious disease can also develop in animals kept in captivity (e.g., macaques). On the other hand, TBE infection is typically asymptomatic in domestic ruminants and does not cause health problems in the infected hosts, but infected lactating animals are a risk for human health. TBEV in the milk of infected goats, sheep, and cows can serve as a source of TBE infection via the alimentary route. Therefore, pasteurisation or boiling of milk is a basic preventive measure to avoid alimentary TBE infection in humans. The vaccination of selected domestic animal species in the future is proposed to avoid the development of severe TBE symptoms in sensitive animals (e.g. dogs, horses) or to decrease the risk of alimentary infection in humans (e.g. small ruminants).

Acknowledgments. The authors acknowledge financial support from the Ministry of Agriculture of the Czech Republic (grant project QK1920258) and the Ministry of Industry and Trade of the Czech Republic (grant project FV40076).

\section{References}

Balling A, Plessow U, Beer M, Pfeffer M., Ticks Tick Borne Dis. 5, 805-809, 2014. https://doi.org/10.1016/j.ttbdis.2014.06.007

Balogh Z, Egyed L, Ferenczi E, Bán E, Szomor KN, Takács M, Berencsi G., Intervirology 55, 194-200, 2011. https://doi. org/10.1159/000324023

Berrada ZL, Telford SR., Top Companion Anim. Med.24, 175-181, 2009. https://doi.org/10.1053/j.tcam.2009.06.005

Blaškovič, D., Epidémia encefalitídy v Rožňavskom prírodnom ohnisku nákaz. SAV, Bratislava. 1954.

Bogovic P, Strle F., World J. Clin. Cases 3, 430-441, 2015. https:// doi.org/10.12998/wjcc.v3.i5.430
Böhm B, Schade B, Bauer B, Hoffmann B, Hoffmann D, Ziegler U, Beer M, Klaus C, Weissenböck H, Böttcher J., BMC Vet. Res. 13, 267, 2017. https://doi.org/10.1186/s12917017-1192-3

Caini S, Szomor K, Ferenczi E, Szeklyne Gaspar A, Csohan A, Krisztalovics K, Molnar Z, Horvath J., Euro Surveill. 17, pii: 20128, 2012.

Chambouris R, Sixl W, Stünzner D, Köck M., Geogr. Med. 3, 11-14, 1989.

Cisak E, Wójcik-Fatla A, Zając V, Sroka J, Buczek A, Dutkiewicz J., Ann. Agric. Environ. Med. 17, 283-286, 2010.

Csángó PA, Blakstad E, Kirtz GC, Pedersen JE, Czettel B., Emerg. Infect. Dis. 10, 533-534, 2004. https://doi.org/10.3201/ eid1003.020734

Dryden MW., Vet. Dermatol. 20, 435-440, 2009. https://doi.org/ 10.1080/14739879.2009.11493831

Füzik T, Formanová P, Růžek D, Yoshii K, Niedrig M, Plevka P., Nature Com. 9, 436, 2018. https://doi.org/10.1038/ s41467-018-02882-0

Grešíková M, Havárnek I, Gorner F., Veter. Cas. 9, 462-469, 1960. Grešíková M., Acta Virol. 2,113-119,1958a.

Grešíková M., Acta Virol. 2, 188-192,1958b.

Grešíková M., Cesk. Epidemiol. Mikrobiol. Imunol. 8,26-32,1959.

Grešíková M., Klieštova encefalitída - trvalý verejno-zdravotnícky problém. Veda, SAV, Bratislava, 1999.

Grešíková M., Veter. Cas. 5, 177-182, 1957.

Gritsun TS, Lashkevich VA. Gould EA., Antiviral Res. 57,129-146, 2003. https://doi.org/10.1016/S0166-3542(02)00206-1

Heinz FX., Adv. Virus Res. 31, 103-168, 1986. https://doi. org/10.1016/S0065-3527(08)60263-8

Hekrlová A, Kubíček O, Lány P, Rosenbergová K, Schánilec P., Berl. Munch. Tierarztl. Wochenschr.128,397-401, 2015.

Holzmann H, Aberle SW, Stiasny K, Werner P, Mischak A, Zainer B, Netzer M, Koppi S, Bechter E, Heinz FX., Emerg. Infect. Dis. 15, 1671-1673, 2009. https://doi.org/10.3201/ eid1510.090743

Hudopisk N, Korva M, Janet E, Simetinger M, Grgič-Vitek M, Gubenšek J, Natek V, Kraigher A, Strle F, Avšič-Županc T., Emerg. Infect. Dis. 19, 806-808, 2013. https://doi. org/10.3201/eid1905.121442

Kerbo K, Donchenko I, Kutsar K, Vasilenko V., Euro Surveill. 10, E050623.2, 2005. https://doi.org/10.2807/ esw.10.26.02740-en

Kerlik J, Avdicova M, Stefkovicova M, Tarkovska V, PantikovaValachova M, Molcanyi T, Mezencev R., Travel Med. Infect. Dis. 26, 37-42, 2018. https://doi.org/10.1016/i. tmaid.2018.07.001

Klaus C, Beer M, Saier R, Schau U, Moog U, Hoffmann B, Diller R, Süss J., Ticks Tick Borne Dis. 3, 27-37, 2012. https:// doi.org/10.1016/j.ttbdis.2011.09.011

Klaus C, Hoffmann B, Beer M, Müller W, Stark B, Bader W, Stiasny K, Heinz FX, Süss J., Ticks Tick Borne Dis. 1, 141-144, 2010. https://doi.org/10.1016/j.ttbdis.2010.06.001

Klaus C, Hörügel U, Hoffmann B, Beer M., Vet. Microbiol.163,368372, 2013. https://doi.org/10.1016/j.vetmic.2012.12.041

Klimes J, Juricová Z, Literák I, Schánilec P, Trachta e Silva E., Vet. Rec. 148, 17-20, 2001. https://doi.org/10.1136/vr.148.1.17 
Kritz G, Leschnik M, Leidinger E., Kleintierpraxis 46, 151-160, 2001.

Kř́̌ž B, Beneš C, Daniel M., Epidemiol Mikrobiol. Imunol. 58, 98-103, 2009.

Król ME, Borawski B, Nowicka-Ciełuszecka A, Tarasiuk J, Zajkowska J., Przegl. Epidemiol.73, 239-248, 2019.https:// doi.org/10.32394/pe.73.01

Kunz C., Vaccine 21, S50-55,2003. https://doi.org/10.1016/S0264410X(02)00813-7

Leschnik M, Feiler A, Duscher GG, Joachim A., Par. Vector 6:62, 2013. https://doi.org/10.1186/1756-3305-6-62

Leschnik MW, Kirtz GC, Thalhammer JG., Int.J. Med. Microbiol. 291, 66-69, 2002. https://doi.org/10.1016/S14384221(02)80014-5

Levanov L, Vera CP, Vapalahti O., Ticks Tick Borne Dis. 7, 979-982, 2016. https://doi.org/10.1016/j.ttbdis.2016.05.002

Lindhe KE, Meldgaard DS, Jensen PM, Houser GA, Berendt M., Acta Vet. Scand. 51, 56, 2009. https://doi. org/10.1186/1751-0147-51-56

Lindquist L, Vapalahti O., Lancet 371, 1861-1871, 2008. https:// doi.org/10.1016/S0140-6736(08)60800-4

Matuszczyk I, Tarnowska H, Zabicka J, Gut W., Przegl. Epidemiol. 51, 381-888, 1997.

Nuttal PA, Jones LD, Labuda M, Kaufman WR., J. Med. Entomol. 31, 1-9, 1994. https://doi.org/10.1093/jmedent/31.1.1

Paulsen KM, Granquist EG, Okstad W, Vikse R, Stiasny K, Andreassen ÅK, Stuen S., PLoS One 19, e0226836, 2019. https://doi.org/10.1371/journal.pone.0226836

Paulsen KM, Stuen S, das Neves CG, Suhel F, Gurung D, Soleng A, Stiasny K, Vikse R, Andreassen ÅK, Granquist EG., Zoonoses Public Health 66, 216-222, 2019. https://doi. org/10.1111/zph.12554

Pfeffer M, Dobler G., Par. Vector 4, 59, 2011. https://doi. org/10.1186/1756-3305-4-59

Pogodina V., Probl. Virol. 5, 304-310, 1960.

Pogodina V., Vopr. Virusol. 3, 295-299, 1958.

Reiner B, Grasmück S, Steffen F, Djuric N, Schindler T, Müller W, Fischer A., Int. J. Med. Microbiol. 291, 234, 2002. https:// doi.org/10.1016/S1438-4221(02)80069-8

Rieille N, Klaus C, Hoffmann D, Péter O, Voordouw MJ., BMC Vet Res 13, 217, 2017. https://doi.org/10.1186/s12917-017$1136-\mathrm{y}$
Roelandt S, Heyman P, De Filette M, Vene S, Van der Stede Y, Caij AB, Tavernier P, Dobly A, De Bosschere H, Vyt P, Meersschaert C, Roels S., Vector Borne Zoonotic Dis. 11, 1371-1376, 2011. https://doi.org/10.1089/vbz.2011.0647

Rushton JO, Lecollinet S, Hubálek Z, Svobodová P, Lussy H, Nowotny N., Emerg. Infect. Dis. 19,635-637,2013. https://doi. org/10.3201/eid1904.121450

Ruzek D, Avšič Županc T, Borde J, Chrdle A, Eyer L, Karganova G, Kholodilov I, Knap N, Kozlovskaya L, Matveev A, Miller AD, Osolodkin DI, Överby AK, Tikunova N, Tkachev S, Zajkowska J., Antiviral Res.164, 23-51,2019. https://doi. org/10.1016/j.antiviral.2019.01.014

Salat J, Mihalca AD, Mihaiu M, Modrý D, Ruzek D., Emerg. Infect. Dis. 23, 2065-2067, 2017. https://doi.org/10.3201/ eid2312.170166

Salát J, Formanová P, Huňady M, Eyer L, Palus M, Ruzek D., Vaccine 36, 7257-7261, 2018. https://doi.org/10.1016/j. vaccine.2018.10.034

Schwaiger M, Cassinotti P., J. Clin. Virol.27,136-145,2003.https:// doi.org/10.1016/S1386-6532(02)00168-3

Simmonds P, Becher P, Bukh J, Gould EA, Meyers G, Monath T, Muerhoff S, Pletnev A, Rico-Hesse R, Smith DB, Stapleton JT., J. Gen. Virol. 98, 2-3, 2017. https://doi. org/10.1099/igv.0.000672

Širmarová J, Tichá L, Golovchenko M, Salát J, Grubhoffer L, Rudenko N, Nowotny N, Růžek D., Ticks Tick Borne Dis. 5, 523-527, 2014. https://doi.org/10.1016/j.ttbdis.2014.03.008

Süss J, Gelpi E, Klaus C, Bagon A, Liebler-Tenorio EM, Budka H, Stark B, Müller W, Hotzel H., Emerg. Infect. Dis. 13, 905-907, 2007. https://doi.org/10.3201/eid1306.061173

Tipold A, Fatzer R, Holzmann H., Kleintierpraxis 38, 619-628, 1993.

Weissenböck H, Suchy A, Holzmann H., Acta Neuropathol. 95, 361-366, 1998. https://doi.org/10.1007/s004010050811

Yu C, Achazi K, Möller L, Schulzke JD, Niedrig M, Bücker R., PLoS One 9, e96957, 2014. https://doi.org/10.1371/journal. pone.0096957 